\title{
"I THEN FOR THE FIRST TIME FELT FEARFUL SHE MIGHT NOT RALLY...": A DISCOURSE ANALYSIS OF THE NINETEENTH CENTURY CASE REPORTS IN OPHTHALMOLOGY
}

\author{
MAGDALENA ZABIELSKA
}

\begin{abstract}
The present paper constitutes a qualitative discursive investigation of the nineteenth century case reports from ophthalmology derived from a specialist American medical journal, and focuses on citation as well as on authorial and patient's presence. Regarding the first aspect, the present study generally confirms the results of the previous research, i.e. significant subjectivity, directness and informal character of the texts at hand. However, it also provides another insight into the scholarly communication in the nineteenth century, focusing on how patients are positioned therein, which has not received significant attention in the literature of the subject. Additionally, the paper offers an overview of the studies on specific aspects of scientific prose of the nineteenth century, including the medical context, as well as attempts to show the relation between the texts analysed and the context of their production and functioning, following the tradition of Genre Rhetorical Studies.
\end{abstract}

Key words: discourse, genre, case report, ophthalmology, author, patient

\section{Historical and theoretical background}

In the following section, firstly a short historical background will be offered in order to sketch the context in which the texts under study were written. Then an overview of different diachronic studies of scientific genres will be provided, moving from scientific discourse in general, through ophthalmological texts, to case reports in particular, thereby adopting the top-bottom perspective. Finally, the relevance of Genre Rhetorical Studies for the current study will be discussed. 


\subsection{Nineteenth century in medicine}

The period of interest can be called "a golden age" (Ramos, 2006: 115) for medicine as it was becoming the "medicine of observation" (Sournia, 1994: 696). The turn of the nineteenth century marked an important moment in the history of medicine. Thanks to a greater role of autopsies and, subsequently, pathological anatomy, disease came to be understood as changes in the patient's body that could be directly observed. It was when doctors' diagnostic procedures turned from speculation, partly based on patients' accounts, to observation, which entailed the recognition of the signs of disease. The observation of signs of disease also lay at the heart of a new medical institution, namely the clinic.

The evolving practice of observation was accompanied by the invention of revolutionary diagnostic tools, such as the stethoscope, which gradually made the process of medical assessment more and more precise. In the context of ophthalmology, the ophthalmoscope made it possible to inspect the interior of the eye. More specifically, it "not only enabled the physician to observe and classify abnormalities of the retina, but it proved to be extremely valuable in the measurement of errors of refraction in the eye" (Ramos, 2006: 116; cf. Ramos, 2008: 73-75). As will be demonstrated in the empirical part of the paper, this historical conditioning had a bearing on the form and content of the texts at hand.

Originally proposed by Foucault (1969/2002), the importance of the corresponding context in the analysis of discourse has been addressed also by other researchers (e.g. Fairclough and Wodak, 1997; O'Halloran, 2003). The authors claim that discourses are anchored in concrete circumstances of their use and linked to various domains of people's lives. It is these circumstances that dictate what and how is communicated as well as what kind of practices of production and reproduction of discourses are adjacent to texts at hand. Moreover, it has been emphasised that the relation between contexts and texts is dialogic, in that the first affect the other and vice versa (Gee, 1999). This twofold relation was addressed by Bazerman in his influential work Shaping written knowledge. The genre and activity of the experimental article in science (1988), in which his research focus fell on scientific discourse. According to Fairclough (2003), generally, discourse may be understood as language which stands in relation to and is part of social reality $(2003: 3,26)$. What is more, discourse relates to social reality representationally in the form of individual discourses which are grounded in specific contexts. Consequently, scientific discourse may comprise modes of talking and writing about objects, phenomena, notions, etc., dealt with in numerous scientific areas. In his work, Bazerman (1988) demonstrates how knowledge-mediating is socially constructed, i.e. conditioned by the intellectual atmosphere of the time and various accompanying practices. The claim about scientific discourse is validated by the analyses of individual genres. The relevance of the context is also of primary interest to the theory of Genre Rhe- 
torical Studies (Berkenkotter and Huckin, 1995). According to Artemeva and Freedman (2008), it is

a powerful theoretical framework for illuminating research into the historical evolution of genres, the creation of specific genres in response to evolving socio-cultural, ideologi$\mathrm{cal}$, and political circumstances, and the acquisition of genres by novices to new communities of discourse.

In a similar vein, Berkenkotter's (2009) qualitative "wide-angle" approach takes into consideration both micro- and macro-perspectives - the textual layer (language and structure) and the professional practices in which these texts are embedded. This methodological commitment allowed her to study extensively the significance and use of case reports in psychiatry.

In the context of the current paper, the genre of interest is viewed as a constantly evolving entity structure- and language-wise, and these changes are the reflection of the evolution of medicine as an area of research and practice, as well as of technological progress. What these changes concerned was, to name just a few, the intellectual climate of the period, the size of the academia and readership, and the invention of diagnostic tools and discovery of drugs, etc. This will be exemplified below in an overview of the relevant studies on the topic.

\subsection{Historical angle in the research on scientific (medical) discourse}

Atkinson (2001) traced progressive changes in scientific discourse on the basis of the papers published in the Philosophical Transactions of the Royal Society of London, yet the time frame of the texts in his corpus was the period between 1675 and 1975. As the author points out, features of the texts shifted from one pole to the other, namely from involved, author-centred and narrative-like to informational, object-centred and abstract (Atkinson, 2001: 61-63). Consequently, Atkinson's study (2001) demonstrates significant progress within scientific discourse which brought it closer to the form known to contemporary readers. Moreover, Atkinson (2001) seeks to relate these changes to social and historical contexts in which science was developing (cf. Atkinson, 1996). In Valle's (1997) study of the articles derived from Philosophical Transactions of the Royal Society of London from life sciences (including medicine) of the period at hand, addressed clearly defined topics, aimed at the scientific community (as opposed society in general) and developed a relatively explicit purpose of the text, additionally becoming more and more detailed (Atkinson, 1996: 348). In her discipline-specific study, Salager-Meyer (1999) reports that the articles from medical journals of the nineteenth century are characterised by more direct criticism creating the so-called "oppositional discourse" (Atkinson, 1996: 348), belonging to author-centered and privately-based medicine. 
Such a state of affairs can be attributed to the fact that the texts of the time were written records of discussions taking place among specialists, thereby retaining the features of oral exchange of information (the use of present tense in a narrative-like text), which is referred to as "involved production" by Biber (1988) and "the rhetoric of immediate experience" by Atkinson (1996: 359). Also Skelton (1997) in his study of hedging in a corpus of the articles derived from the British Medical Journal reports that the texts from the nineteenth century feature more truth-value statements, as opposed to hedges, which additionally are expressed with the first-person singular (Skelton, 1997: 52). As for referential behavior, also studied by SalagerMeyer (1999) in the same corpus of texts, the nineteenth century texts are characterised by verbatim quotes, and general and specific references. As regards the latter feature, some authors tended to be economical when citing other people, for instance: "Mr. Walter Beer, the celebrated oculist, last house physician, of Vienna, ..." (1823), which can be characterised as "[t]he undateness and undocumentedness of general references" (Salager-Meyer, 1999: 300). It was due to "individually and privately based non-specialised medicine" of those times, as Salager-Meyer and Zambrano (2001: 161) observe, when the authors knew well the materials cited or even their authors. Others, on the other hand, were more precise in their acknowledgement of sources, for instance: "Mr. J. Ronald Martin, in his excellent work "The Influence of Tropical Climates," ... (1816)." Gunnarsson (2009) adds that the nineteenth century authors were more likely to refer to and analyse other scientists' research, and evaluate it. Yet, these judgments were not severe and were accompanied by the author's own questioning (2009: 70). With respect to the form of evaluation, the progressive disappearance of the 'I' form was taking place, in some cases replaced by the 'we' form. Furthermore, Gunnarsson (2001) observes that the perspective that the authors adopted was that of the watching doctor, not of the patient, as it was the case in the previous century (2001: 125; 132-133). Finally, in their study of titling and authorship, Salager-Meyer and Alcaraz Ariza (2013) point to a number of features of the titles of case reports of the nineteenth century: relatively short (i.e. less detailed), semantic and syntactically simple as regards authorship, and usually authored by single scholars.

As regards the ophthalmological discourse, Ramos (2006) compares two ophthalmological manuals - from the fourteenth and nineteenth centuries - with respect to their macrostructure and language. As regards the former aspect, she observes that in comparison to the text from the fourteenth century, the one from the nineteenth century no longer has the part devoted to prognosis. This can be explained by the fact that the nineteenth century was the period of rapid development of diagnostic techniques of various types which allowed doctors to identify diseases and not only speculate about them. Diagnosis then is followed by a description of treatment by means of specific drugs, also not available back in the fourteenth century. Regarding the language, with the already mentioned progress 
in medicine of the nineteenth century, new information delivered by new diagnostic means meant the need and subsequent presence of more and more sophisticated vocabulary.

As regards case-related genres specifically, it is also interesting to note that the nineteenth century was the time when recording cases became a regular practice (Rylance, 2006). In her study of the nineteenth century Canadian gynecological case histories ${ }^{1}$, Nowell-Smith (1995) demonstrates how the above-discussed innovations in medicine were reflected in language. The use of passive voice, a well-known feature of scientific discourse in general, was supposed to render facts in an objective way, regardless of who presented them (cf. Grice and Kramer-Dahl, 1992: 73). Authorial presence needs to be mentioned at this point as well, as it had some consequences also for patient imaging. Nowell-Smith (1995) maintains that patients who are referred to as themes of physicians' actions are not imaged as active participants, which was the case, however, in Hippocratic writings (Nowell-Smith, 1995: 85). Another novel feature of the nineteenth century gynecological case histories is that the texts are entitled, usually naming the patient's illness, for example "Acute Bright's disease, accompanying pregnancy; miscarriage, peritonitis, death, autopsy" (Nowell-Smith, 1995: 54). Absent in Hippocratic case reports, this characteristic enables the author to state the cause of a problem with a single label, which locates the patient's condition along the axis of normal/abnormal (Nowell-Smith, 1995: 54; cf. French, 2003: 191-192; Hurwitz, 2006: 229-230). Yet another feature of those texts is the use of statistics. According to Nowell-Smith (1995), the end of the nineteenth century saw the introduction of numerical information concerning "birth, death, and disease" (1995: 59). Apart from their primary function which was to add credibility to a document, they contributed to the order of information which was presented (Nowell-Smith, 1995: 59-61). Additionally, as Rylance (2006) notes,

[t]he technical information is delivered in a syntactically clipped, unconstrued form appropriate to a specialist readership that seems to be an ancestor the machine-gun delivery of such data in modern medical dramas like ER.

In their diachronic study (2000) of case reports from two periods - 1850-1900 and 1965-1995, Taavitsainen and Pahta (2000) demonstrate that case reports were subject to similar changes as scientific texts in general (Atkinson, 2001). Firstly, the

\footnotetext{
${ }^{1}$ There is a number of genres dealing with cases of diseases and the difference among them regards the context of their use. These are: case presentation, case history/record and case report. Following Fleischman (2001: 477), a case history "includes information on how the patient's condition was noticed and diagnosed, how the condition has been treated, and how the patient responded to treatment. Psychosocial aspects of the case are presented (if at all) only after the medical problems have been discussed". Case reports, on the other hand, are fully-fledged publications, often consisting of constituent parts typical of research papers (Abstract, Introduction, Methods, Results, etc.). Separate article sections describing a given case may also appear under the label of case report.
} 
case reports from the nineteenth century are characterised by two levels of narration, the former is the writer's narration in the first person, i.e. from his point of view, while the latter gives an account of the patient's disease in the third person and foregrounds his/her symptoms (2000: 63-64). The patient's part

is told in a vivid style with illuminating details such as remarks on the patient's looks, frame of mind, and expectations, evaluating attributive adjectives such as judicious [original emphasis] and similes depicting the symptoms of the illness (Taavitsainen and Pahta, 2000: 65),

which points to the fact that authors had not ceased using unusual vocabulary. Yet, though both written by a physician, the two parts differ in the mode of writing with the doctor's narrative more effaced. What is also important is that the patient's level of narration is less prominent and it serves as an addition to the account of physician's judgements and decisions (Taavitsainen and Pahta, 2000: 64, 66). Secondly, the texts from the first investigated period are characterised by a more involved style underscoring the presence of an author, whereas the texts from the latter period appear more impersonal and detached. Taavitsainen and Pahta (2000) attribute this transformation to changes in the scientific community in that it grew more numerous as education and knowledge in general became more accessible. Similar results regarding the narrative and involved character of rhetoric reflected in the use of first person markers, specific references, emotionally-charged expressions and quotes were also obtained by Helán (2012) in his small-scale analysis of the nineteenth century case reports from the British Medical Journal. This "emotional" character could also be observed when physicians conveyed their attitude towards the patient's lifestyle, in this case at the beginning of case histories (Rylance, 2006). Thirdly, the intellectual climate needs to be emphasised as well. In the case reports from the nineteenth century essential was how a physician decided on treatment on the basis of the diagnosis. On the other hand, the emergence of new diagnostic tools, statistical analyses and studies based on larger populations affected the writers' choice of the presented data (Taavitsainen and Pahta, 2000: 72-73), resulting in the so-called "careful itemisation of symptoms" and "depreciating the patient's individuality" (Rylance, 2006). Consequently, the compelling narratives about the incredible were transformed into concise and conventionalised accounts based on scientifically verifiable facts (see also Murawska, 2013, Zabielska, 2014 and Zabielska, 2015, for a more detailed historical background of the genre of the medical case report). This change is well captured by Sacks (1986), who observes that "[t]he tradition of richly human clinical tales reached a high point in the nineteenth century, and then declined, with the advent of an impersonal neurological science" (1986: xiv). 


\section{Data}

The current small-scale corpus consists of 22 case reports derived from the Transactions of the American Ophthalmological Society, a publishing outlet for the society, now an annual peer-reviewed journal. The articles included were published in the period between 1865-1870 and were the oldest case reports available in the online version of the journal. The length of the articles varies from one to seventeen pages. As regards the titles, these are primarily names of diseases or conditions, often in the form of "The case of...". Gunnarsson (2009) observes that that modern medical articles are characterised by a unified structure of Introduction, Material, Methods, Results, Discussion and Conclusions, whereas earlier texts were structured according to their content (2009: 65). The majority of the case reports in the corpus are not divided into sections. Only when the reports describe multiple cases are these cases separated and marked, either as Case 1, Case 2, In another instance of... (three articles), etc., or with the patient's surname and age (one article). Few texts are structured in a very simple way, for example following the days of the patient's treatment (four articles) or separating Ophthalmoscopic examination, Execution, or Diagnosis (three articles). Whereas the division into Cases and dates can be compared rather to a content-driven structure, the sections devoted to Execution or Diagnosis are the sings of moving towards a unified structure.

\section{Methods}

The texts were examined qualitatively with respect to textual references to patients, i.e. the words indexing patients (woman, she) as well as any other manifestation forms (leg, case) that were used, following the approach to studying patient's presence proposed in Zabielska (2014). The focus fell also on authorial presence and its functions, and, in this case, Tang and John's (1999) approach was adopted.

\section{Results and discussion}

The following sections will be devoted to particular aspects of the studied texts, i.e. authorial and patient's presence as well as references to them, each featuring relevant examples.

\subsection{Authorial presence}

According to Hyland (2002), "academic writing (...) not only conveys disciplinary 'content"' (2002: 1092). It is also an arena of various metadiscursive activities. The authors do not only merely 'describe' but also 'explain', 'persuade' and 'guide' 
their readers through the text in order to make the process of reading easier. Following this line of reasoning, a number of studies have been conducted to identify these roles to demonstrate the authors' discursive activities. In the following analysis of authorial presence in the texts under investigation, Tang and John's (1999) classification of the functions of first person singular and plural pronouns which mark the author's perspective, has been adopted. It was successfully applied in Carciu's (2009) study of biomedical research articles published in international English-medium journals, with some author's modifications as regards the classification. The very classification was developed by Tang and John (1999) on the basis of students' essays as well as on academic articles and books in linguistics, and consisted of the following roles: Representative, Guide, Architect, Opinion Holder and Originator. Although alternative classifications were proposed (Vassileva, 1998; Kuo, 1999; Sheldon, 2009), the one adopted seems to reflect best the actual instances in the corpus.

As the analysis of the case reports in the corpus shows, the authors of the articles mark their textual presence, first through using various variants of the first person pronoun 'I', and second, by resorting to the adjectives which carry subjective opinion, which confirms the already noted tendency of the nineteenth century authors to convey their subjective evaluations as perceptions of the cases at hand. It needs to be emphasised that in the present corpus, the authors were marked primarily by means of the first person pronoun. The very few instances of the use of 'we' referred to the author and the accompanying doctor, but in no case did they refer to a group or researchers or people in general.

First, the different roles of the authorial persona will be exemplified and discussed.

\subsubsection{Author's roles}

Firstly, Tang and John (1999) differentiate between the role of the Architect and the Guide. Whereas the Architect navigates readers within the very text, defining, elaborating or describing, the Guide refers to mental operations such as observing, seeing and noting (Halliday, 1994). Therefore, as Carciu (2009) rightly observes drawing on Hyland (2005), the former and latter role can be characterised as textand reader-oriented, referring to "the text as text" and to "the text as study, theory, argument" (Hyland, 2005: 45) respectively (Carciu, 2009: 75). The following examples illustrate this distinction:

1) By anaesthesia of the cornea I here refer [ARCHITECT] to that diminution of its sensitiveness to touch which may exist without apparent organic disturbance of the part. ${ }^{2} \mathrm{TO}^{3}$

\footnotetext{
${ }^{2}$ All the examples from the texts analysed were given in their original form, including instances of double spaces and occassional spelling mistakes.
} 
2) As this is a case of remarkable interest, and, to my knowledge, the first on record, I shall report [ARCHITECT] it in considerable detail. TO8

3) I have noticed [GUIDE] several times a singular phenomenon: the simple contact of the clothing often provokes the most unspeakable torture, and yet the skin has superficially a kind of insensibility, which lasts often long after the pains have ceased. TO11

4) In every reported example, of this affection, it has been noticed [GUIDE] that both the arteries and the veins of the retina were greatly reduced in size. TO18

In example (1), the author "refers" to a particular medical aspect and the word "here" specifically signals that the reference happens within the text and for its purposes and not outside it. (2) is the same case, as the author promises to report "the" case in considerable detail. The role of the Guide refers the reader to the author's observation (cf. 3). However, in the corpus, there are only few instances of personal pronouns 'I' with this role. Instead, the impersonal construction is often used, as in (4).

The role that the authors of the studied texts seem to adopt very frequently is the Opinion holder, where, by means of such verbs as 'think' or 'believe' (Carciu, 2009: 86), they express their views. However, the linguistic realisation of these examples in the corpus at hand is slightly different.

5) I would operate [OPINION HOLDER] in all such cases when anesthesia of the cornea could not be relieved by atropia, and especially when the pupil had become undilatable, and then maintain the elects of the operation by the uwe of atropia. TO1

6) I consider [OPINION HOLDER] that these experiments are very satisfactory. TO8

7) The theory which appears to me [OPINION HOLDER] to explain most satisfactorily the morbid phenomena in question, is that which assumes the primary lesion to have been an extravasation of blood into the sheath of the optic nerve, between the globe and the optic commissure. TO18

Whereas in (6) and (7), the linguistic resources are the words consider and appear respectively, which are typical of the realisations of this role, in example (5), the opinion/preference is expressed with the help of a modal verb. Yet another way is when a subjective view is expressed not so much with the use of verbs of belief but rather by means of specific adjectives which convey this subjective perception (cf. examples $8-13$ below).

8) The whole lens had a most beautiful iridescent appearance, which was greatest in the line of the main fissure. TO8

\footnotetext{
${ }^{3}$ Each publication analysed was assigned a code and a complete list of the texts can be found in Primary sources.
} 
9) The patient was very intelligent and readily consented to aid my search. She kept a record of the quantity of urine passed per diem, and sent me specimens twice weekly. TO15

10) In the other case the cornea assumed a sloughy look on the second dayperhaps, I feared, on account of dampness of the room occupied by the patient. TO20

11) I wondered if he saw the beautiful changes of scene and color which people experience when hanged, as so often described. TO8

12) I have found it a little troublesome to distinguish a slight lifting up of the retina when the subjacent fluid was transparent and the retina not opalescent. TO17

13) By the time the pain ceased the patient was very much enfeebled and emaciated, and I then for the first time felt fearful she might not rally. TO11

In the final example given above, the author resorts to expressing his fears. These instances also confirm the results obtained by Taavitsainen and Pahta (2000) in their study of the nineteenth century case reports (cf. section Historical angle in the research on scientific (medical) discourse above).

The remaining two roles proposed by Tang and John (1999) are the Recounter and the Originator. As regards the former, there are examples in which authors portray themselves as mere recounters of the procedures/steps they had to undertake in the course of a given treatment. The presence of the authorial persona in the description of methods seems of particular interest in the light the fact that it is precisely methods that are contemporarily described in a rather effaced manner (Lores Sanz, 2011). The rationale behind such a practice is that in scientific discourse, the focus falls on the execution of a given procedure, so that it can be replicated and tested, and it should not matter who performs it .

14) I treated [RECOUNTER] her with mild antiphlogistics. TO5

15) Two weeks later, there being no relief, but rather an aggravation of the pain, I extirpated [RECOUNTER] the eye-ball. TO6

16) I tested [RECOUNTER] the urine and found absolutely no albumen and abundant sugar. TO15

17) I lacerated [RECOUNTER] the retina in the same manner that we tear a capsular cataract. TO17

18) Oct. 5, 1863, the patient having been etherized, the operation was performed. In attempting to transfix the eye with a tenaculum, the bony substance subsequently revealed was encountered. Prof. Graefe, of Berlin, as a means of diagnosia, recommends percussing upon the ball with a hard substance. The eye, being now secured with a pair of claw forceps, the conjunctiva was incised around a circumference an eighth of an inch from the edge of the cornea. The tendons of the muscles, one after another, raised 
upon a blunt hook, were snipped off with scissors from the bulb. The optic nerve being severed with a pair of long curved scissors, the eye was lifted out and enucleation completed. Recovery, as usual in such cases, was rapid and complete. $\mathrm{TO} 7$

In examples (14-17), the authors describe particular procedures they performed. Yet, such examples where the author refers directly to himself when giving an account of treatment methods, are relatively rare in the corpus at hand; instead the descriptions of how a patient was treated tend to be impersonal, with passive voice constructions, as in (18). Therefore, while the author is textually present in introducing a given case, establishing diagnosis and discussing implications, the technical part remains rather detached. Nevertheless, it seems interesting to note that there are examples of Methods sections, possibly the most impersonal and technical section of the case report genre, where the first person perspective is adopted. Admittedly, such a practice emphasises the uniqueness/success of the method/experiment developed by the author.

The final author's role is that of the Originator, where the author presents himself as the one who introduces new ideas, approaches, methods, etc. In the belowgiven examples, this role is marked by means of possessive pronouns:

19) My own solution of the present case [ORIGINATOR] would be as follows: at first, hemorrhage within the heath of the optic nerve, compressing suddenly the nerve fibres, the central artery and vein. TO18

20) My design [ORIGINATOR] is to show the importance of making an exact correction of each eye by itself, not doubting that when each is made as perfect as possible it will be ready to co-operate with its fellow in binocular vision. TO2

Examples such as (19) and (20) above, where the focus shifts from the author to his own solution and intention respectively, according to Hyland (1997), go against the assumed objectivity of science and allow the author to stress his own opinion as well as to offer readers the possibility to decide upon their ultimate judgment (1997: 27; cf. Myers, 1989: 14). This goes in line with the previous studies of the nineteenth century scientific texts (Atkinson, 1996; Taavitasinen and Pahta, 2000) and significantly greater presence of the author therein.

Tang and John (1999) identify one more role, i.e. that of the Representative. Writers may adopt this role when they use the pronoun 'we' or its variant to refer to people in general. However, this role was not attested in the present corpus.

In conclusion, it can be said that the identified author's roles in the medical case reports orchestrate with Tang and John's (1999) classification. Drawing on Ädel's (2006: 20) terminology, Carciu (2009) divides the roles into two categories, i.e. those referring to the "real world" and the world of "text". This way, the roles of the 
Recounter and the Originator refer to the "real world" of a given course of treatment and novel procedures respectively. On the contrary, the Architect and the Guide refer to the reality of the "text", i.e. the Architect to the author's structuring of the material within the article, and the Guide to the author's interaction with the reader meaning what the author 'shows', 'notes', 'observes', etc. The role of the Representative, not attested in the corpus, can be subsumed under the category of the world-oriented categories.

\subsection{References}

As has been already stated, Salager-Meyer (1999) observed that the nineteenth century medical texts are characterised by verbatim quotes as well as general and specific references. The results of the study at hand seem to confirm this finding:

21) With reference to Dr. Allin's case, Mr. President, it may warrant sufficient interest to report the course of the iris cyst which I operated on last year, and made mention of at the last meeting of this society. TO5

22) Prof. Graefe, of Berlin, as a means of diagnosia, recommends percussing upon the ball with a hard substance. TO7

23) The whole appearance closely resembled cases in Prof. Knapp's „Intraocular Tumors.” TO9

24) Dr. M. Singer records a case of herpes zoster following all three branches of the fifth, and in which it was observed that the two senses of touch and taste in the tongue disappeared and reappeared in strict unison, thus giving strong corroboration to the idea that the lingual is a nerve of taste. (Biennial Retrospect of Medicine.) TO11

25) I will finish with the following quotation from the British Medical Journal, Vol. i., 1866, p. 470, as it applies to two cases in Mr. Hutchinson's table and to the plate published by the Sydenham Society. TO11

26) In looking over the authorities I find that several-Cazenave, Erasmus Wilson, Hardy, Fuchs, Neligan and Tilbury Fox-speak specially of ulceration and gangrene possibly occurring, particularly in old people, from herpes zoster. Fuchs alone says: „It may be fatal. This result has been but seldom observed. Fr. Hoffman had two fatal cases from gangrene. It may also occur from metastasis, or ulceration and hectic fever." TO11

27) I will here quote from Prof. Hebra, with whom the recent Englislh and French authorities agree. He says: ,Under herpes zoster I include all those skin affections which present the character of herpes, and in which the part of the surface occupied by the groups of vesicles corresponds to the distribution of certain cutaneous nerves, and which, lastly (whether occurring on 
the head, trunk or limbs), are confined to one-half of the body. It is only in rare and exceptional instances that herpes zo8ter attacks both sides simultaneously." TO11

28) In the Medical Times and Gazette (Vol. l., pp. 111, 112) Mr. Wharton Jones alludes to the ill effects produced in cases of acute glaucoma by the application of belladonna, and warns against its use. TO13

29) In Mauthner, Lelhrbuch der Ophthalmoscopie, 1868, p. 375, it is' said: „Edward Jaeger found retinitis in an individual who suffered from diabetes mellitus. A connection between diabetes and retinitis has since that time by some (Virchow, Freytag, Nagel) been declared to be possible, and by others (Martin, Galezowski) been positively asserted. TO15

In the above-given list, different types of references to other authors have been identified. In examples (21-24), the reference is given to individual doctors/ physicians, with an exact location in (22), and particular sources in (23) and (24). It should also be noted that the very form of reference to these people assumes that they were widely recognised and no other more specific information about them was necessary. (25) is a reference to a particular text in a journal (similarly to 24), whereas (26) and (27) contain direct quotations. Finally, (28) and (29) are complete references in that they send the reader to a particular person and a source. Therefore, a scale of references from more general to specific can be observed, i.e. from references to particular people only, through sources and to the combination of an author plus a source. More specific references also point to the fact that the then medical discourse community was expanding and thus referring only to individual Doctors Xs or Professors Ys was no longer the practice (cf. Taavitsainen and Pahta, 2000: 72-73; cf. Helán, 2012: 176).

Concluding this section, the analysis of authorial presence and references in the nineteenth century case reports from ophthalmology demonstrate significant subjectivity, directness and informality, which confirms the features identified in the scientific discourse of the period as reported in the literature on the topic (see section Historical angle in the research on scientific (medical) discourse above).

\subsection{Patient's presence}

In this section, the many ways in which patients are referred to textually in the case reports at hand will be presented, following the approach to examining patient's presence in contemporary case reports from various areas of medicine in Zabielska (2014). In this study, both direct (nouns and personal/possessive pronouns) and indirect (patient's body parts and the word 'case') references to patients were examined. Additionally, a scale of these references was proposed, following from the most prominent ones (the patient presented as a whole person) to those which, in a way, 
hide the patient behind the text (references to the patient's body or aspects of condition/treatment as well as distancing devices). This scale was also adopted in the current analysis and the following section will start from the examples of the most patient-centered mode of reference and will progress towards different modes of abstraction from him/her.

\subsubsection{Patient's perspective}

This type of reference allows one to introduce the patient's perspective which, though in the third-person, gives voice to the experience of illness.

30) He first noticed this strange behavior after painting miniatures for some time by tlle aid of an imperfect convex lens. TO3

31) From this period be remembered to have suffered no very great pain or discomfort in it until about a year before he consulted me, when the complaint became violent. TO7

32) The patient states that there has been increased pain the last three weeks, during which time the tumor has appeared and grown. TO9

33) She attributed the trouble to special exposure to cold on the day previous to the attack. TO10

34) On the 13th of November, 1865, I was consulted by a medical friend, who told me that, while dressing himself a few hours previously, he had suddenly felt his left eye "dazzled" by the light of the sun. TO18

35) A physician of the place gave her some „eye drops”, which she had continued to use, but without relief. TO12

36) When pain gradually came on, and soon became a prominent symptom, which increased to such an extent that he was obliged to give up all work. TO20

37) Enucleation was advised, but the patient refused to submit to the operation. $\mathrm{TO} 22$

In all the above-given examples, the patients described occupy the subject position in the sentences, therefore it is their perspective that is presented. In example (36), although the patient is not the Agent of the sentence, thanks to the passive voice construction, it is still possible to retain his perspective. Also, in all the examples except for (37), patients' experience of illness is acknowledged, from the relatively mild expressions such as "great pain or discomfort", as in (31), to rather subjective, such as "strange" in (30) or "violent" in (31). It is possible that these were the patients' exact words, however, they are not marked in any way that would indicate so, which is practiced in today's case reports. Only examples (34) and (35) contain the words "dazzled" and "eye drops", placed in quotation marks, which may 
suggest that these were the patients' exact words. Significant use of such quotations was noted by Helán's (2012) in his study. In (31), (33) and (37), there are examples of the patients presented as active participants in the processes of diagnosis and treatment.

\subsubsection{Patient as location}

38) In 1856, Virchow gave the results of a post mortem examination of two women, who had died of puerperal fever, in each of whom he discovered evidences of acute disease of the interior of the eyeball, depending upon the presence of emboli in the arterial vessels; and he then predicted that many cases of amaurosis, occurring in connection with valvular disease of the heart, would find their true explanation in this occurrence. TO18

In the above given example, the patient is referred to directly and as a whole person, but the perspective is shifted to the object of study and the patient serves as a location of the described phenomena. This mode of patient reference is an example of the metaphor of CONTAINER, which is frequently used in medical texts (cf. Lakoff and Johnson, 1980; Fowler, 1996; Murawska, 2010). It allows one to describe patients as locations where diseases are identified and treatment performed. It is a useful linguistic resource to draw attention to the disease at hand, but, at the same time, still maintaining the patient in 'linguistic sight'.

\subsubsection{Focus on body-parts}

39) The iris is to be tested by using a given number of drops of atropia in solution of definite strength. TO1

What is meant by 'focus on body parts' are sentences in which patients' body parts, organs, tissues, etc. are the primary topics, accompanied by possessive pronouns or nouns in the possessive or not. This type of patient reference may be attributed to one of the most important developments in the history of medicine, namely pathological anatomy. Virchow (1821-1902), one of the greatest pathologists, claimed that disease targets not whole organs but tissues and added that tissues' reaction to disease causes their dysfunction. This led Virchow to the claim that disease is an altered condition of tissues and cells (Blois, 1984: 110), which, in turn, resulted in the explosion of microscopic studies of bodily constituent parts (Margotta, 1996: 158). With the underlying assumption that it was tissues and cells where illness was to be sought, "organs assumed centre stage, and patients' views were retained as prefatory material" (Nowell-Smith, 1995: 52). 


\subsubsection{Patient as case}

The word 'case' occurs very frequently in case reports, usually to denote individual occurrences of particular diseases. However, some authors may choose the word to refer directly to patients, which, in turn, images not the patient as being treated but a particular disease (cf. Zabielska, 2014).

40) The above cases represent the pathological conditions under observation, and show the results of division of the ciliary ring upon them after general and local medical treatment, aided in a number of them by frequent and systematic-paracentesis of the cornea, had failed. TO1

41) In two other cases the pupil, quite undilatable, yielded upon administering ether to a high grade of relaxation. we describe cases. TO1

While in example (40), the word "case" stands for an occurrence of the disease, in example (41), the word "case" can be changed for the word 'patient'.

\subsubsection{Abstraction from the patient}

This type of patient reference includes those sentences which refer to the aspects of the patient's condition and treatment, abstracting textually from the treated person.

42) On admission there was complete opacity of the lens, the pupil was irregularly dilated and altered in color, a great amount of venous congestion, extreme tension of the ball, no perception of light, and pain almost constant, referred principally to the globe and back of the head. TO6

43) With the removal of the eye-ball there was an entire relief of all pain, and no return of the disease since. TO6

44) This application did not afford relief. There were occasional remissions, but no real intermissions of the pain, as in true hemicrania. TO11

45) Two weeks later, there being no relief, but rather an aggravation of the pain. TO21

46) Medical treatment had failed to afford relief. TO1

47) In one case, soon after a piece of metal had been thrown into an eye, the second eye became inflamed and atrophied, vision being totally destroyed, and yet the subsequent removal of the foreign body was followed by quite good vision in the injured eye. TO13

48) At evening, with the aid of Dr. Agnew, who held the upper lid, I performed the operation. The patient, placed under a gas-light, and the eye illuminated by a mirror attached by an elastic band to my forehead, a broad, doubleedged needle was entered between the superior and external recti muscles, 
and advanced until its point was distinctly seen in the vitreous humor; it then was plunged into the highest part of the retinal sac, and the point carried backwards to enlarge the perforation. Blood at once flowed into the vitreous. Applied a compress and bandage. TO17

In example (42), a group of symptoms is presented. In examples (43-45), pain is mentioned, yet the patient who experiences this pain is not textually present. In (44-46), similarly to pain, also relief is mentioned. In sentences (42-45), impersonality and detachment is achieved by empty discourse themes (Lores, 2004). (47) is a longer fragment which focuses only on the patient's eye, however, nowhere in this text is the reference to the patient present. Finally, (48) refers to the aspect that has already been discussed, i.e. the description of methods of treatment (cf. section Authorial presence above). In such accounts, usually the author-evacuated (Geertz, 1988) discourse is used. In this example, however, the author announces himself at the very beginning, claiming the position of the doctor, and then what follows, is the impersonal text, with multiple passive voice constructions.

As can be seen, the examples of modes of patient presentation, originally identified in contemporary case reports from various areas of medicine (Zabielska, 2014) were also found in case reports from the nineteenth century from ophthalmology. This stands in contrast to the already examined status of authorial presence in the texts being markedly different from contemporary professional medical discourse.

\section{Conclusion}

The following paper offered a discursive analysis of selected features regarding authorial and patient's presence as well as citation in a collection of medical case reports from ophthalmology from the nineteenth century. Such aspects as the roles the authors of the texts assume in order to mediate knowledge, how other scholars are cited as well as how patients are indexed, were examined, in line with the assumptions of Genre Rhetorical Studies. These elements were discussed with reference to the context of the production and functioning of the texts at hand, i.e. the status of the development of medicine, as well as compared to the current mode of writing case reports. The study confirms the results of previous studies of the nineteenth century medical discourse in that the reports display features not present in contemporary case reports, i.e. significant subjectivity, directness and informality, which reflected the then conditioning of medicine and the very doctor in general. Yet, the reports studied in some respects also remind of case reports from the twenty-first century, especially in the way patients are referred to there. 


\section{References}

Ädel, A. 2006. Metadiscourse in L1 and L2 English. Amsterdam: John Benjamins.

Artemeva, N. and A. Freedman. 2008. "Introduction". In: Artemeva, N. and A. Freedman (eds.). Rhetorical genre studies and beyond. Winnipeg: Inkshed Publications. 143-188.

Atkinson, D. 1996. "The "Philosophical Transactions of the Royal Society of London 1675-1975: a sociohistorical discourse analysis". Language in Society 25 (3). 333-371.

Atkinson, D. 2001. "Scientific discourse across history: a combined multi- dimensional/rhetorical analysis of the Philosophical Transactions of the Royal Society of London". In: Biber, D., Conrad, S. and R. Reppen (eds.). Corpus linguistics: investigating language structure and use. Cambridge: Cambridge University Press. 45-65.

Bazerman, C. 1988. Shaping written knowledge. The genre and activity of the experimental article in science. Madison: The University of Wisconsin Press.

Berkenkotter, C. 2009. "A case for historical "wide-angle" genre analysis: a personal retrospective". IBÉRICA 18. 9-22.

Berkenkotter, C. and T. Huckin. 1995. Genre knowledge in disciplinary communication: cognition/culture/power. Hillsdale, NJ: Lawrence Erlbaum Associates.

Biber, D. 1988. Variation across speech and writing. Cambridge: Cambridge University Press.

Blois, M.S. 1984. Information and medicine. Berkeley: University of California Press.

Carciu, O.M. 2009. "An intercultural study of first-person plural references in biomedical writing". IBÉRICA 18. 71-92.

Fairclough, N. 2003. Analysing discourse. Textual analysis for social research. London: Routledge.

Fairclough, N. and R. Wodak. 1997. "Critical discourse analysis". In: van Dijk, T.A. (ed.). Discourse as social interaction. Vol. 1. London: Sage Publications. 258-284.

Fleischman, S. 2001. "Language and medicine”. In: Schiffrin, D., Tannen, D. and H.E. Hamilton (eds.). The handbook of discourse analysis. Oxford: Blackwell Publishers. 470-502.

Foucault, M. 1969/2002. The archeology of knowledge. London: Routledge.

Fowler, R. 1996. Language in the news: discourse and ideology in the press. London: Routledge.

French, R. 2003. Medicine before science. Cambridge: Cambridge University Press.

Gee, J.P. 1999. An introduction to discourse analysis: theory and method. New York: Routledge.

Geertz, C. 1988. Words and lives: the anthropologist as author. Palo Alto, CA: Stanford University Press.

Grice, F. and A. Kramer-Dahl. 1992. "Grammaticalising the medical case history". In: Toolan, M. (ed.). Language, text and context: essays in stylistics. London: Routledge. 56-90.

Gunnarsson, B.-L. 2001. "Expressing criticism and evaluation during three centuries". Journal of Historical Pragmatics 2 (1). 115-139.

Gunnarsson, B.-L. 2009. Professional discourse. London: Continuum.

Halliday, M.A.K. 1994. An introduction to functional grammar (2nd edition). London: Edward Arnold.

Helán, R. 2012. Analysis of published medical case reports: Genre-based study. Unpublished PhD dissertation. Brno: Masaryk University.

Hurwitz, B. 2006. "Form and representation in clinical case reports". Literature and Medicine 25 (2). 216-240.

Hyland, K. 1997. "Scientific claims and community values: articulating an academic culture". Language and Communication 17. 19-31.

Hyland, K. 2002. "Authority and invisibility: authorial identity in academic writing”. Journal of Pragmatics 34 (8). 1091-1112.

Hyland, K. 2005. Metadiscourse: exploring interaction in writing. London: Continuum. 
Kuo, C.-H. 1998. "The use of personal pronouns: role relationships in scientific journal articles". English for Specific Purposes 18. 121-138.

Lakoff, G. and M. Johnson. 1980. Metaphors we live by. Chicago: The University of Chicago Press.

Lores, R. 2004. "On RA abstracts: from rhetorical structure to thematic organization". English for Specific Purposes 23. 280-302.

Lores-Sanz, R. 2011. "The construction of the author's voice in academic writing: the interplay of cultural and disciplinary factors". Text and Talk 31 (2). 173-193.

Margotta, R. 1996. History of medicine. London: Hamlyn.

Murawska (Zabielska), M. 2010. "Figures, grounds and containers. Patient presentation in medical case reports”. Miscelánea: A Journal of English and American Studies 41. 77-91.

Murawska (Zabielska), M. 2013. "Personal and sensational vs. impersonal and objective - a historical overview of patient presentation in medical case reports". Tekst i dyskurs - text und diskurs 6. 185-202.

Myers, G. 1989. "The pragmatics of politeness in scientific articles". Applied Linguistics 10. 1-35.

Nowell-Smith, H. 1995. "Nineteenth-century narrative case histories: an inquiry into stylistics and history". CBMH/BCHM 12. 47-67.

O'Halloran, K. 2003. Critical discourse analysis and language cognition. Edinburgh: Edinburgh University Press.

Ramos, M.J.E. 2006. "Medical terminology across the centuries: distinctive features of a chronological study in the field of ophthalmology". IBÉRICA 12.111-126.

Ramos, M.J.E. 2008. English medical vocabulary in ophthalmology. Muenchen: Lincom.

Rylance, R. 2006. "The theatre and the granary: observations on nineteenth-century medical narratives". Literature and Medicine 25 (2). 255-278.

Sacks, O. 1986. The man who mistook his wife for a hat: and other clinical tales. London: Picador.

Salager-Meyer, F. 1999. "Referential behaviour in scientific writing: a diachronic study (1810-1995)". English for Specific Purposes 18 (3). 279-305.

Salager-Meyer, F. and N. Zambrano. 2001. "The bittersweet rhetoric of controversiality in nineteenthand twentieth-century French and English medical literature". Journal of Historical Pragmatics 2 (1). 141-173.

Salager-Meyer, F. and M.A. Alcaraz Ariza. 2013. "The medical narrative from a diachronic perspective (1840-2009): titling practices and authorship". In: Gotti, M. and C. Sancha (eds.). Narratives in academic and professional genres. Bern: Peter Lang. 293-318.

Sheldon, E. 2009. "From one I to another: discursive construction of self-representation in English and Castilian Spanish research articles". English for Specific Purposes 28. 251-265.

Skelton, J. 1997. "How to tell the truth in the British Medical Journal: patterns of judgement in the 19th and 20th centuries". In: Markkanen, R. and H. Schröder (eds.). Hedging and discourse. Approaches to the analysis of a pragmatic phenomenon. Berlin: Mouton de Gruyter. 42-63.

Sournia, J.C. 1994. "Les phases évolutives du vocabulaire médical français”. Meta 29 (4). 692-700.

Taavitsainen, I. and P. Pahta. 2000. "Conventions of professional writing: the medical case report in a historical perspective". Journal of English Linguistics 28 (1). 60-76.

Tang, R. and S. John. 1999. "The 'I' in identity: exploring writer identity in student academic writing through the first person pronoun". English for Specific Purposes 18. S23-S39.

Valle, E. 1997. "A scientific community and its texts: a historical discourse study". In: Gunnarsson, B.-L., Linell, P. and B. Nordberg (eds.). The construction of professional discourse. Edinburgh: Pearson Longman. 76-98.

Vassileva, I. 1998. "Who am I/who are we in academic writing?". International Journal of Applied Linguistics 8 (2). 163-190.

Virchow, R. 1880. Post-mortem examinations, with especial reference to medico-legal practice. Translated by T. Smith. Philadelphia: Presley Blackiston. 
Zabielska, M. 2014. Searching for the patient's presence in medical case reports. Frankfurt am Main: Peter Lang.

Zabielska, M. 2015. "Patient-centred case reporting: state of the art". In: Zabielska, M., WąsikiewiczFirlej, E. and A. Szczepaniak-Kozak (eds.). Discourses in co(n)text: the many faces of specialised discourse. Newcastle upon Tyne: Cambridge Scholars Publishing. 2-32.

\section{Primary sources}

TO1 Hildreth, J.G. 1866. "Extract from observations upon anesthesia of the cornea and radiating fibres of the iris occurring without intra-ocular tension". Transactions of the American Ophthalmological Society 1 (3). 19-25.

TO2 Noyes, H.D. 1868. “Observations in astigmatism”. Transactions of the American Ophthalmological Society 1 (4-5). 28-29.

TO3 Pomeroy, O.D. "Case of acquired astigmatism". Transactions of the American Ophthalmological Society 1 (4-5). 30.

TO5 Simrock, F. 1870. "A case of cyst of iris". Philosophical Transactions of the Royal Society of London 1 (7). 64-66.

TO6 Morton, W.R. 1868. "Case of encephaloid tumor springing from the fundus of the eye-ball stimulating glaucoma". Transactions of the American Ophthalmological Society 1 (4-5). 39.

TO7 Noyes, J.F. 1868. "Enucleation of eye for sympathetic ophthalmia". Transactions of the American Ophthalmological Society 1 (4-5). 97-98.

TO8 Dyer, E. 1866. "Fracture of the lens of one eye and of the anterior capsules of both eyes from death by violent hanging". Transactions of the American Ophthalmological Society 1 (3). 12-19.

TO9 Jeffries, J. "Rough notes of a case of glio-sarcoma". Transactions of the American Ophthalmological Society 1 (7). 72-73.

TO10 Jeffries, J.B. 1870. "Three cases of herpes zoster frontalis seu ophthalmicus". Transactions of the American Ophthalmological Society 1 (7). 72-73.

TO11 Jeffries, J.B. 1868. “A case of herpes zoster ophthalmicus, in a patient nearly eighty years of age, causing fatal prostration". Transactions of the American Ophthalmological Society 1 (4-5). 75-91.

TO12 Allin, C.M. 1866. "Case of sudden monocular amaurosis". Transactions of the American Ophthalmological Society 1 (3). 10-12.

TO13 Derby, H. 1868. "Mydriatics in glaucoma". Transactions of the American Ophthalmological Society 1 (4-5). 35-38.

TO15 Noyes, H.D. 1868. "Retinitis in glycosuria". Transactions of the American Ophthalmological Society 1 (4-5). 71-75.

TO17 Noyes, H.D. 1866. "Cases of sub-retinal effusion - puncture". Transactions of the American Ophthalmological Society 1 (3). 36-42.

T18 Sands, H.B. 1866. "Sudden monocular amaurosis, presenting unusual difficulties in diagnosis". Transactions of the American Ophthalmological Society 1 (3). 2-10.

TO20 Williams, H.W. 1868. "Suture of the wound of cornea after flap extraction - report of forty-four cases". Transactions of the American Ophthalmological Society 1 (4-5). 58-61.

TO22 Roosa, J.D.B. Sr. 1869. "Vascular tumor of iris, probably sarcomatous, with colored plate". Transactions of the American Ophthalmological Society 1 (6). 14-15. 